\title{
RANS modelling of some strongly swirling aerospace flows
}

\author{
Timothy J. Craft, Hector Iacovides and Brian E. Launder ${ }^{a}$ \\ School of MACE, University of Manchester, PO Box 88, Manchester M60 1QD, UK
}

Received 20 April 2009

\begin{abstract}
Progress is reported on the modelling, via RANS closures, of two swirling turbulent flows important in aeronautics: the trailing wing-tip vortex and the flow in rotor-stator cavities. For the former the decay of the vortex is only well captured at second-moment level while, for the latter, an unsteady flow computation brings out large-scale organized structures, with the number of structures varying with cavity aspect ratio and Reynolds number, a result qualitatively in accord with experiment.
\end{abstract}

Key words: Modelling / RANS / fluids dynamics unsteady flows / large-scale organized structures

Résumé - Modélisation par RANS des écoulements turbulents tourbillonnaires en aéronautique. Les développements récents sur les fermetures du type RANS sont présentés concernant deux écoulements turbulents tourbillonnaires importants en aéronautique : le tourbillon d'extrémité en bord de fuite d'aile et l'écoulement de rotation en cavités rotor-stator des turbomachines. Pour le premier la décroissance de l'énergie du vortex n'est bien capturée qu'au niveau du moment d'ordre deux tandis que pour le second, un calcul en écoulement instationnaire met en évidence les structures organisées à grande échelle, dont le nombre de structures dépend de l'allongement de la cavité et du nombre de Reynolds, résultat qualitativement en accord avec l'expérience.

Mots clés : Modélisation / RANS / écoulements instationnaires / écoulements en rotation / couche d'Ekman

\section{Introduction}

The paper summarizes progress in the numerical computation of two important classes of turbulent, swirling aerospace flows that have been the focus of steady or unsteady RANS studies in Manchester over the past five years: the wingtip vortex and the flows within rotating disc cavities. In our computations, as in the experiments with which they are compared, the flow is incompressible.

\section{The wing vortex study}

The initial stage of the wing-vortex study concerned the initiation and very early development of the vortex shed from a NACA 0012 wing with rounded tip at a $10^{\circ}$ angle of attack. Computations were made with the STREAM 3D elliptic solver [1] extending from 1.74 chord lengths upstream of the wing and continuing to 0.68

\footnotetext{
a Corresponding author:

brian.launder@manchester.ac.uk
}

chords downstream. Half-a-dozen turbulence models were tested by [2] ranging from the standard $k$ - $\varepsilon$ linear EVM to second-moment closure. Downstream from the airfoil, in the tip-vortex wake, greatly different behaviour was recorded by the different models, Figure 1, with the best agreement with the experiments of [3] being achieved by the TCL second-moment closure (designed so that each modelled term is consistent with the Two-Component Limit with which turbulence must comply at a wall, [4]).

Thereafter, attention was shifted to the EU C-Wake Project which provides data from a NACA 4412 main profile with a NACA 0012 flap at $20^{\circ}$ taken up to 10 wingspans downstream (i.e. 100 times as far downstream, in dimensionless terms, as that of Fig. 1). In this case the TCL model again led to very satisfactory agreement with experiment, Figure 2 [5].

\section{Rotating flow in gas-turbine cavities}

The second class of problems is related to flow in the cavities found in gas-turbines between adjacent turbine 

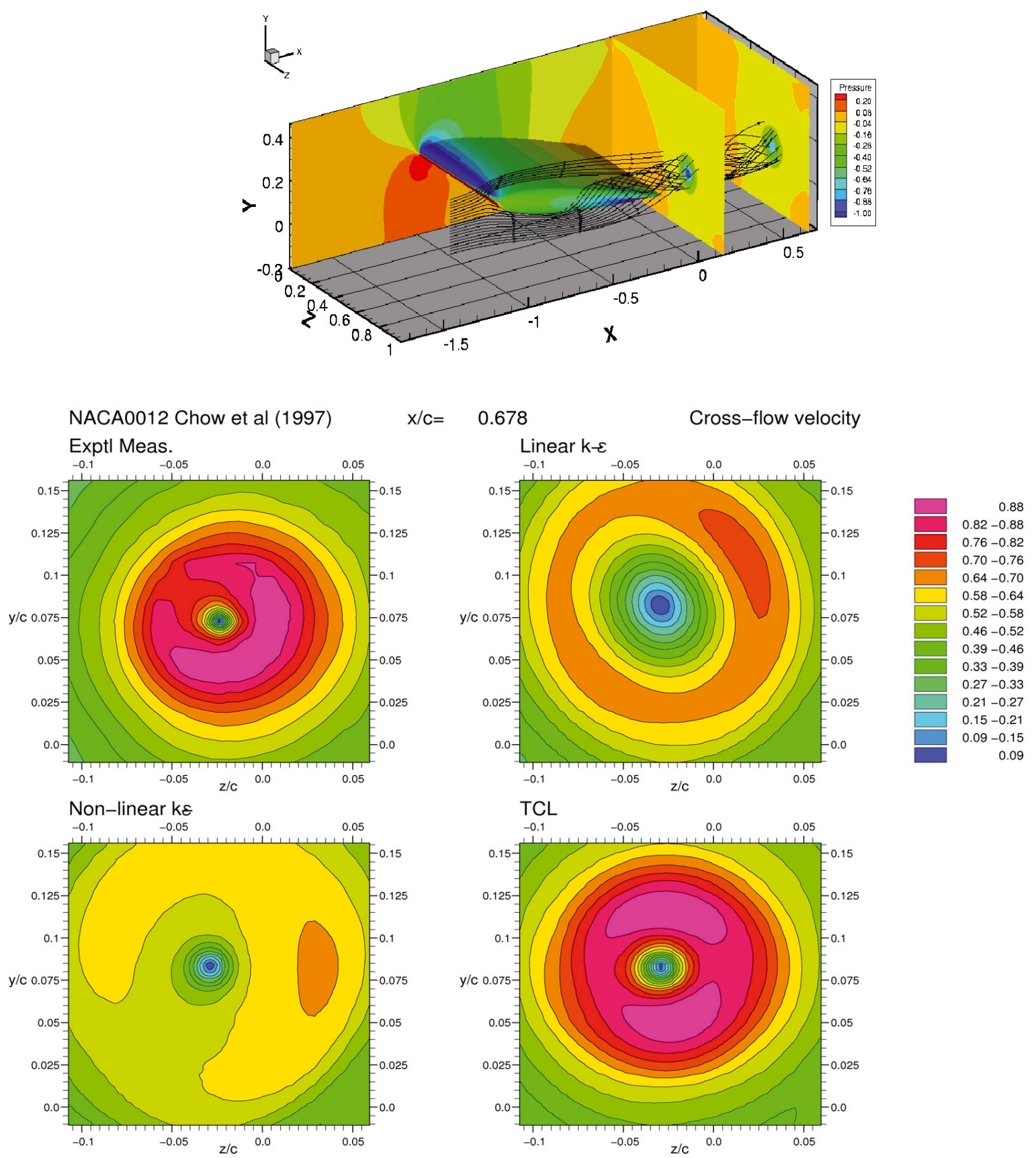

Fig. 1. (a) Flow configuration, (b) comparison of swirl velocity contours 0.678 chord-lengths downstream of airfoil. From top left in cyclic order: experiments, [3]; linear $k-\varepsilon$ EVM; TCL $2^{\text {nd }}$ moment closure; non-linear $k-\varepsilon$ EVM. From [2].

discs which may be rotating or stationary (carrying the blades and guide vanes). While turbulent flows in such cavities had until recently been regarded as axisymmetric and steady, there is evidence [6] that large-scale organized structures are present that may significantly alter the local Nusselt number. Work was thus initiated to try and mimic these structures which rotated at about half the speed of the rotating disc. Again the STREAM code, now in unsteady mode, was employed but using the simpler $k-\varepsilon$ EVM since, if large-scale structures were predicted, these would (it was supposed) mainly be responsible for the transport of momentum in the flow. The initial computations employed a 'low-Reynolds-number' form which extended all the way to the wall. These captured the nearwall structure with Ekman and Bödewadt spirals but no large-scale vortices appeared in the core. The numerical solution was then modified by using a newly developed form of analytical wall function $[5,7]$. This relatively rudimentary near-wall treatment nevertheless allowed skewing of the velocity vector across the sublayers of the discs, 

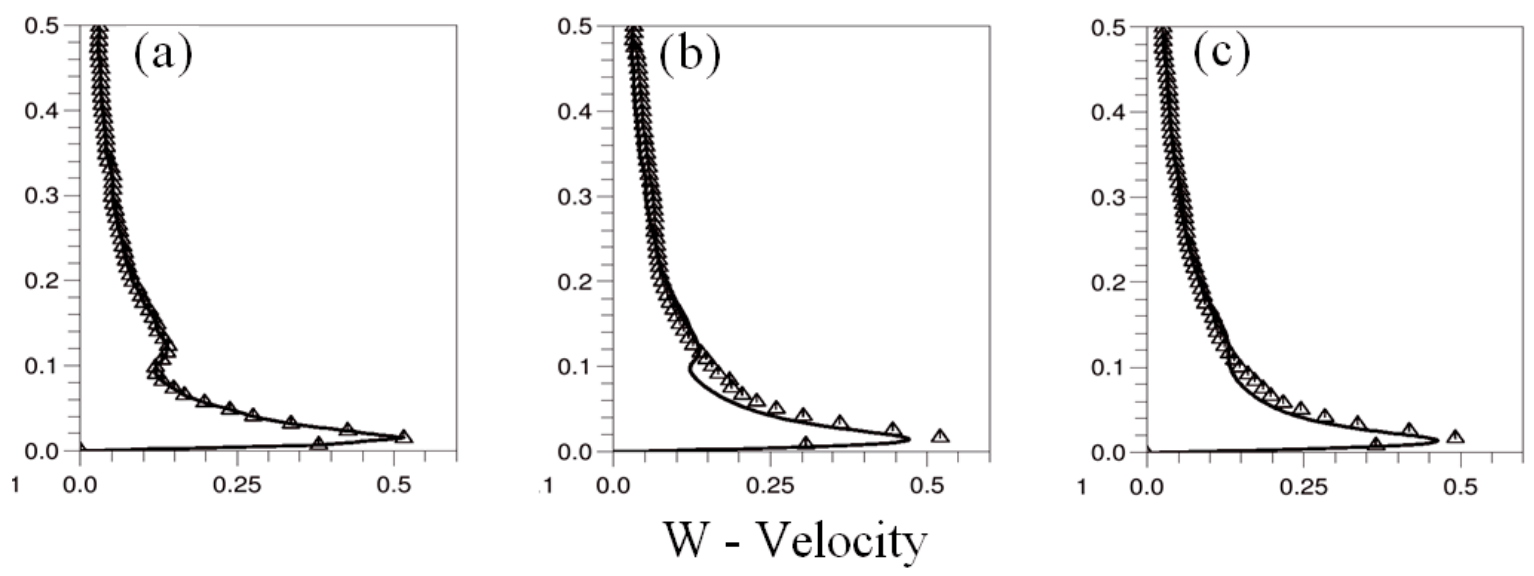

Fig. 2. C-wake swirl velocity at initial, intermediate and downstream planes (a) $x / b=1.25 ;(\mathrm{b}) x / b=5.0 ;(\mathrm{c}) x / b=10.0$. From [5].

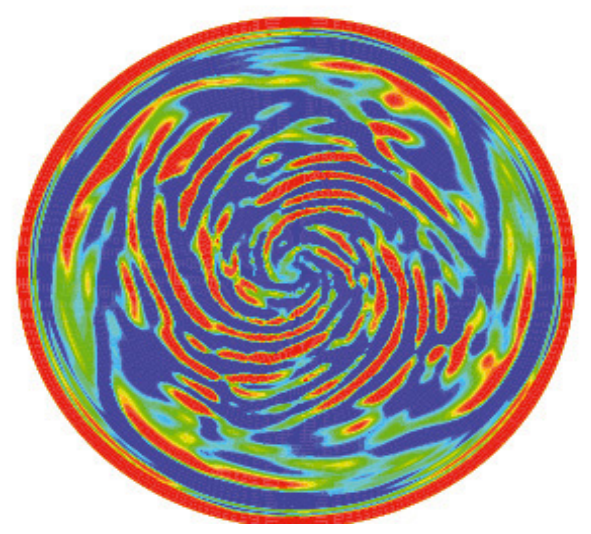

Fig. 3. Predicted structures close to the stationary wall. From [5].

an essential feature to capture. This economical treatment of the sublayers enabled a much finer, more uniform mesh to be employed over the remainder of the flow. Although the detailed flow in the viscous layers was not resolved, this approach achieved a sufficiently accurate resolution of the near-wall region for the Bödewadt spirals to be captured, Figure 3.

Moreover, large-scale vortices were generated in the nearly homogeneous central core outside of the near-disc shear layers, Figure 4. This success was not complete, however, for the multi-cell structures, which formed in the first few revolutions after starting the computations, gradually decayed: the three-vortex structure first collapsed to two and then one of those eddies weakened suggesting that eventually the computed flow would revert to axisymmetric form (the present study has only tracked the flow development for 70 revolutions). In the earlier experiments that stimulated this study, [6], both the threeand the two-vortex structures were a permanent feature of the flow. Further explorations are thus evidently needed to identify and remedy this disagreement.

Computations have also been made for co- and counter-rotating disc cavities, [8]. In the case of two discs co-rotating at the same rate but with a stationary shroud, the large-scale vortices arise only over the outer quarter of the disc radius with the flow within the inner core being nearly axisymmetric, Figure 5. This may be expected since it is in the vicinity of the outer shroud that the flow's angular momentum decreases with radius, a trigger of flow instability. Note, however that the axes of the vortices are in this case transverse to the flow whereas, for the Taylor-Görtler vortices formed in a boundary layer developing on a concave surface, their axes are directed in the primary flow direction around the curved surface. Finally, Figure 6 examines the case of counter-rotating flow with one disc rotating at only half the speed of the faster disc. This test-case has proved troublesome for RANS prediction codes (e.g. Kilic, 1996; [9]) at least partly because the Ekman flow is much stronger on the faster disc and a stagnation point (arising from the collision of the two Ekman layers) occurs at about 0.85 of the disc radius on the slower disc. The circumferentially and temporally averaged radial and tangential velocity profiles from the URANS computations shown in Figure 6a display very satisfactory accord with the experiments of Kilic et al. (1996) in contrast to the axisymmetric RANS calculations with a very similar turbulence model [9], from which paper Fig. 6b has been clipped.

\section{Conclusion}

Swirling turbulent flows commonly give rise to severe problems for accurate prediction with RANS treatments. The paper has summarised progress by the CFD group at the University of Manchester of two such classes of flow. The two-component limit (TCL) second-moment closure has been found to be particularly effective in predicting the trailing swirling wake created behind the tips of wings. For the flow within rotor-stator or rotor-rotor disc cavities an unsteady RANS approach used in conjunction with a new analytical wall-function scheme has enabled the organized vortex structures found in experiments and in 

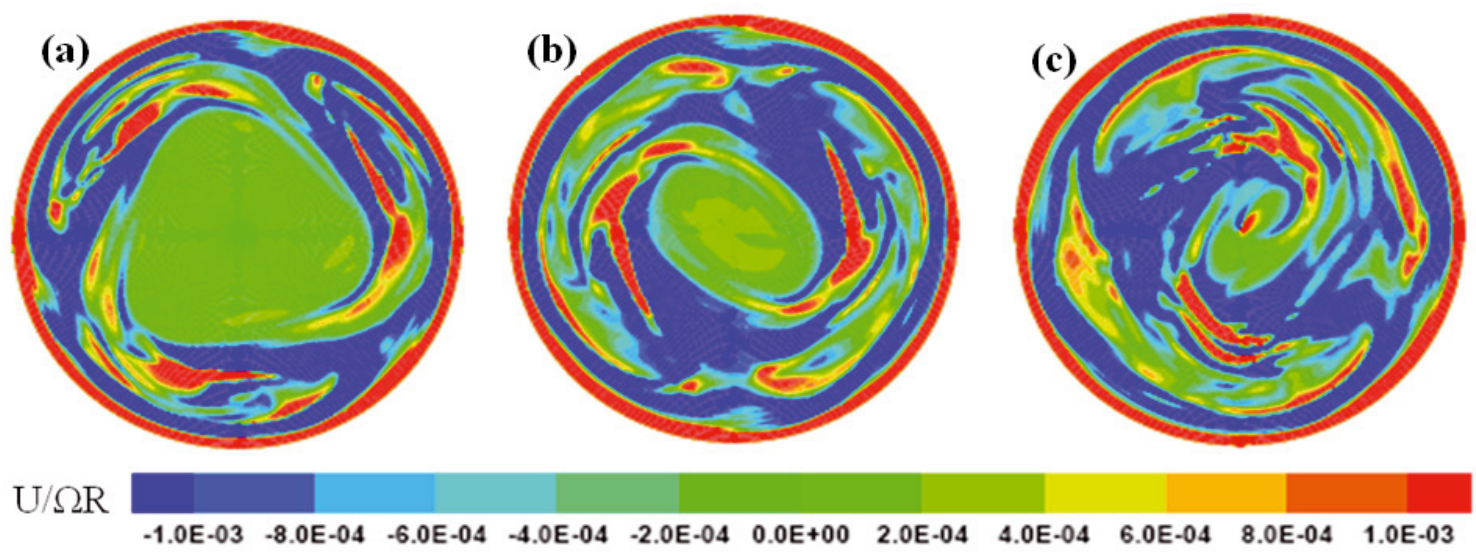

Fig. 4. Evolution of flow structures near the stationary disc for $s / R=0.195, R e=0.9 \times 10^{6}$. Contours of axial velocity after (a) 20 revolutions; (b) 40 revolutions; (c) 70 revolutions. From [5].

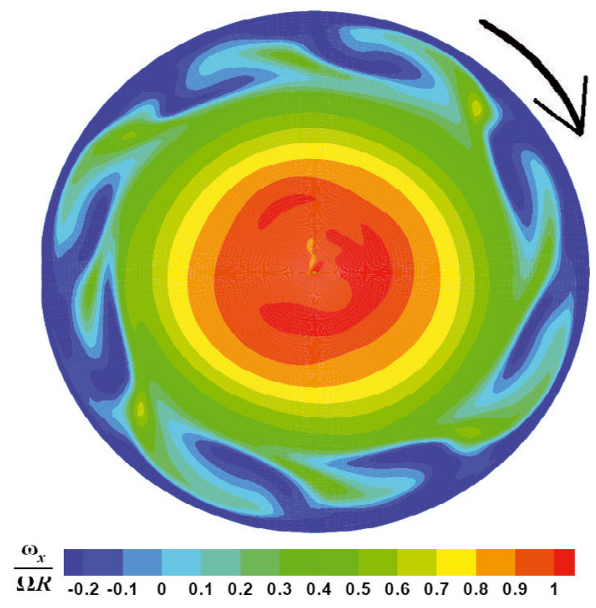

Fig. 5. Contours of instantaneous, circumferential vorticity at the mid-plane $(x / s=0.5)$ of the co-rotating cavity. From [8].
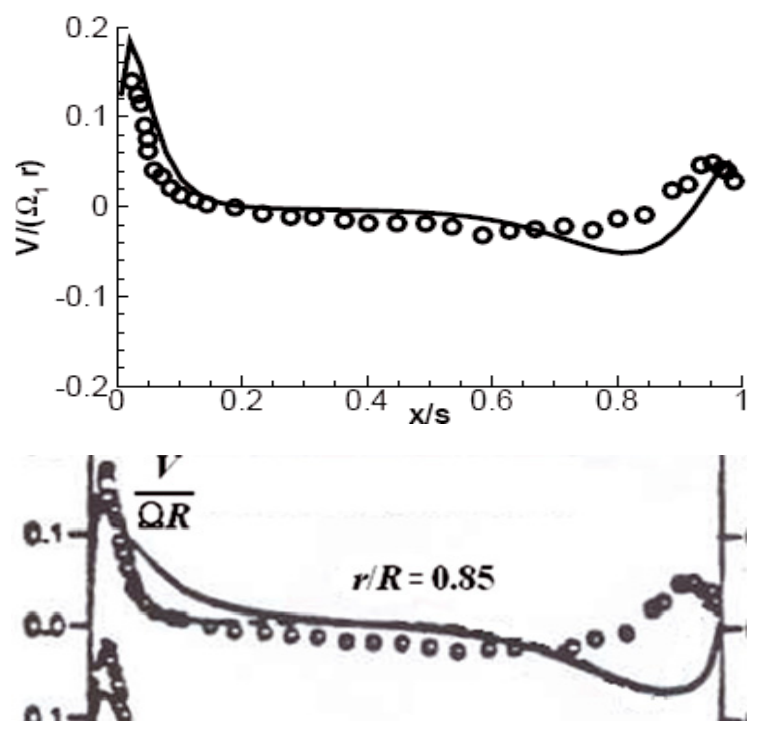

Fig. 6. Computed radial velocity in contra-rotating discs at $r / R=0.85$; disc-rotation ratio - 0.5. (a) $3 \mathrm{D}$ circumferentially averaged URANS; (b) 2D RANS with very similar turbulence model, $[8,9]$.
DNS studies of these types of flows to be captured even though some questions remain to be resolved.

Acknowledgements. It is a pleasure to acknowledge the contributions of former Ph.D. students in the group to the computations summarized above: S.E. Gant, A.V. Gerasimov, C.J. Robinson and A. Zacharos. The research has been supported the UK Engineering \& Physical Sciences Research Council and by the European Union under grant MDAW-UMI-N007. Authors' names are listed alphabetically.

\section{References}

[1] F.-S. Lien, M.A. Leschziner, Upstream monotonic interpolation for scalar transport with application to complex turbulent flows, Int J. Num Meth. Fluids 19 (1994) 527-548

[2] T.J. Craft, A.V. Gerasimov, B.E. Launder, C.R. Robinson, A computational study of the near-field generation and decay of wing-tip vortices, Int. J. Heat Fluid Flow 27 (2006) 684-695

[3] J.S. Chow, G. Zilliac, P. Bradshaw, Turbulence measurements in the near field of ma wingtip vortex, NASA Tech Mem. (1997) 110418

[4] T.J. Craft, N.Z. Ince, B.E. Launder, Recent developments in 2nd-moment closure for buoyancy-affected flows, Dynamics of Atmospheres \& Oceans 25 (1996) 99-114

[5] T.J. Craft, H. Iacovides, B.E. Launder, A. Zacharos, Some swirling flow challenges for turbulent CFD, Flow Turb. Comb. 80 (2008) 419-434

[6] O. Czarny, H. Iacovides, B.E. Launder, Precessing vortex structures in turbulent flow within rotor-stator disc cavities, Flow, Turb. Comb. 69 (2002) 51-61

[7] A. Zacharos, Ph.D. Thesis, School of Mechanical, Aerospace \& Civil Eng'g, University of Manchester, 2009

[8] H. Iacovides, B.E. Launder, A. Zacharos, Proc 6th Turbulence \& Shear-Flow Phenomena Conferece, Seoul, Korea, June 2009

[9] H. Iacovides, K.S. Nikas, M. Te Braak, 1996, Turbulent flow computations in rotating cavities using low-Reynoldsnumber models, Paper No ASME-96-GT-159, Int. Gas Turb \& Aero Congress, Birmingham, UK 